\title{
BRAINSTEM AUDITORY EVOKED RESPONSE
}

\author{
APPLICATION IN NEUROLOGY
}

CARLOS A. M. GUERREIRO *

BRUCE L. EHRENBERG **

Brainstem auditory evoked response (BAER) consist of a sequence of volume-conducted waves recorded at the scalp following a click stimulus to the ear. The BAER was first described by Jewett and associates ${ }^{9}$ in 1971 . These waveforms are very small potentials, about 0,5 microvolts (uV) in amplitude, which compares to the EEG background activity of 20 to several hundred $\mathrm{uV}$.

The evoked potentials (EP) reflect the successive electrical events of the brainstem auditory pathways and are named "far-field" potentials because they are recorded on the scalp, far from the origin. Since they occur with 10 millisecond (msec) after each stimulus they are called "short-latency EP's".

Computer averaging techniques allow extraction of these tiny evoked responses (ER's) from the background noise (EEG, muscle artifact). The seven waveforms most often found are designated as wave I - VII and probably represent the activation of acoustic nerve (wave I), cochlear nuclei (wave II), superior olives (wave III), lateral lemniscus tracts and nuclei (wave IV) and inferior colliculi (wave V) ${ }^{19}$. Waves VI and VII presumably arise, respectively, from the medial geniculate body and auditory radiations to the temporal lobe, but are not considered clinically useful 3 . Emphasis is placed on waves I, III, and $V$ (acoustic nerve, pons and midbrain).

The BAERs are relatively unaffected by sleep, anesthesia, and even doses of barbiturates sufficient to induce coma?.

This paper discusses the basic procedures, the normal responses, the abnormal findings and the indications and value of the BAER.

\section{TECHNICAL CONSIDERATIONS}

The patient lies down in a quiet, dimly lit room. Relaxation or sedation are encouraged to decrease the muscle and movement artifacts. The patient's hearing

* Fellow in Clinical Neurophysiology at Tufts-New Fngland Medical Center (T-NEMC), Boston, Massachusetts, USA; Assistant Professor of Neurology at Campinas University (UNICAMP), são Paulo, Brazil.

** Director of Clinical Neurophysiology, T-NEMC, Boston, MA., USA.

Akcnowledgement: This paper was partially supported by funds of Fundação de Amparo à Pesquisa do Estado de São Paulo (FAPESP). 
threshold to minimal (0-50 decibel (dB) click stimuli is determined, and with the same headphones, repetitive click stimulation of 60 and $75 \mathrm{~dB}$ above threshold is used to produce the BAERs. In a comatose patient, greater $d B$ stimulation may be necessary. Bach ear is tested separately and the opposite ear is masked with white noise ( $30 \mathrm{~dB}$ below the click intensity). Bilateral simultaneous stimulation is sometimes needed in cases of severe hearing impairment. Routinely we use vertex-ipsilateral, and vertex-contralateral-ear lobe as well as ear-to-ear electrode connections. Electrodes are attached with collodion and electroltic paste is used to maintain impedances below 3000 ohms. Click stimuli are produced by applying a 100 microsecond square pulse to the earphones at an 11/second stimulation rate. Rarefaction stimulation is used. Activity is amplified 50,000 or 100,000 times with a band pass filter of 30 to $3000 \mathrm{~Hz}$. The averaging process is displayed on an oscilloscope to monitor artifacts. Ten msec of post-stimulus EEG is averaged over 1024 or 2048 stimuli and registered by an $X-Y$ plotter. Two sets of such stimuli are plotted close together so that waveform variability can be easily assessed. Waves I, III, and V should not vary by more than 80 microseconds between sets, to be considered a stable response. The whole procedure takes about 90 minutes.

\section{NORMAL RESPONSES}

A normal adult test is shown in figure 1. Adequate identification of the components of the BAER is obviously important. The identification, however, is not always clear, e.g., wave $V$ is not necessarily the fifth vertex-positive potencial. Measurements are made of inter-wave separation mainly between the waves $I$, III and V. The normal mean $(\vec{x})$ values for interpeak latencies (IL) of I-V, I-III, and III-V are 4.00, 2.11 and 1.89 msec respectively. The upper limit of normal $(\bar{x}+3$ standard deviiations) for I-V, I-III, and II--V are 4.59, 2.63 , and 2.31 msec respectively. These measurements are made for each ear separately and then compared. A difference between the two sides for the wave I-V IL of greater than $0,5 \mathrm{msec}$ is considered abnormal 2,3.

Amplitude criteria are based on the wave V/I ratio. A normal V/I ratio is more than 0.5. Below the age of about one year, IL are prolonged relative to adult values and vary inversely with age. Several factors may influence the IL: temperature 22, age, sex, stimulus rate and intensity, audiogram shape 23,25 and polarity of the acoustic click stimulation 1. The BAER shows good consistency when followed over time in normal 3.

Despite the abundance of crossed fibers in the human auditory system, the BAERs orignate primarily in structures ipsilateral to the stimulated ear 4. Hearing loss often can be recognized by the BAER since it increases the latency of wave I and thus the absolute latencies of all the subsequent waves. It does not, however, significantly alter the interpeak latencies (IL). This must be considered in the analysis of the results.

\section{INDICATIONS FOR THE BA.RR}

The clinical value of this non-invasive test is in the evaluation of patients with possible disease of the brainstem 17,19. It is worth noting that EEG is usually of 
little value and the CT-scan has its highest incidence of false negatives in brainstem disorders.

\section{CASES FOR ILLUSTRATION}

Case 1 - Normal adult control (figure 1).

Case 2 - A 12 year old female, previously well, with a two week history of headaches on awakening, one week of dizziness, diplopia and nausea, and two days of clumsiness and falling. Neurologic examination revealed a mild left hemiparetic patient with ataxic gait and cerebellar signs on the left. Cranial nerves showed a right VIth nerve palsy and a horizontal left beating nystagmus. CT-scan revealed a posteriorly displaced fourth ventricle, enlarged pons with areas of high and low density, and enlarged lateral ventricles. The BAER is shown in figure 2.

Case 3 - A 20 year old female with progressive gait disturbance since age 3. Examination showed pes cavus deformity bilaterally with hammer toes and Achilles tendon contractures plus bilateral signs of cerebellar, posterior column, pyramidal tract and peripheral nerve involvement. Extensive workup was unremarkable except for the evoked potentials. There were no auditory complaints. BAER (figure 3) showed bilateral diffuse delays. This implies a diffuse brainstem demyelination. A diagnosis of spino-cerebellar degeneration was made.

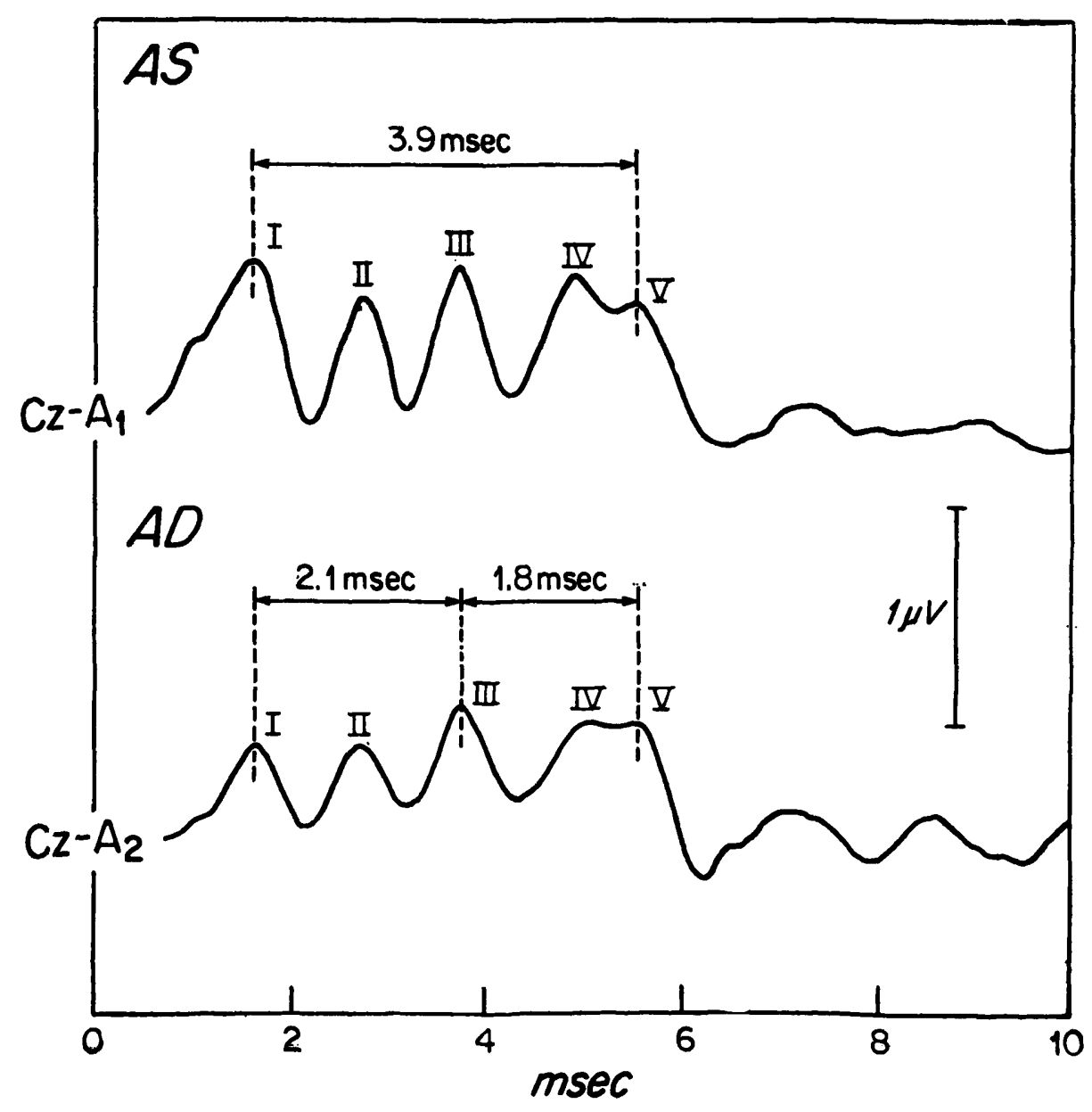

Fig. 1 - Normal adult control: $A \mathrm{~S}=$ left ear stimulation; $A D=$ right ear stimulation. 


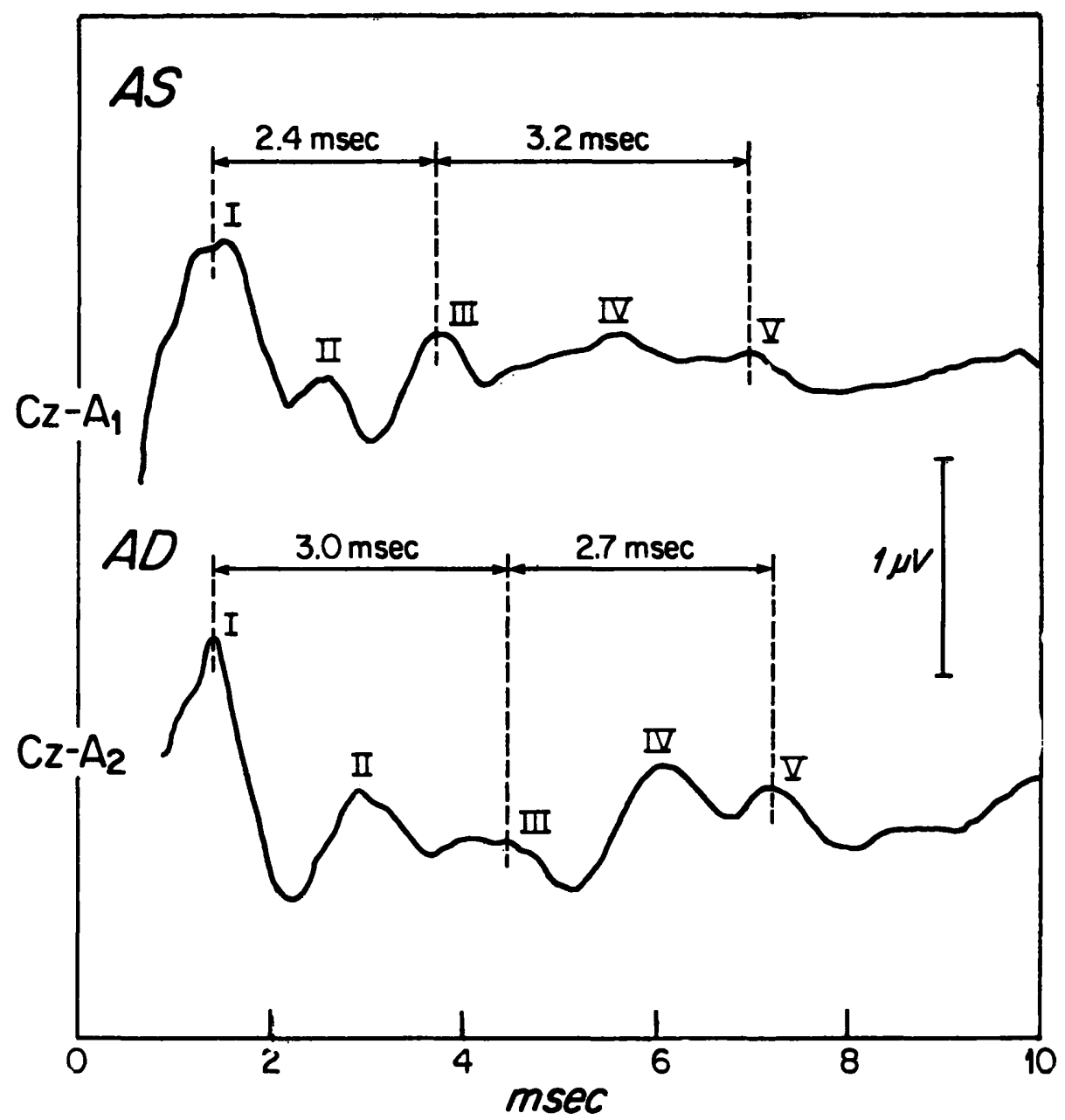

Fig. \& - BAER in presumed pontine glioma. There is marked prolongation of the I-V IL bilaterally, most of which occurs in the earlier waves (I-III). This points to a predominant right ponto-medullary disturbance.

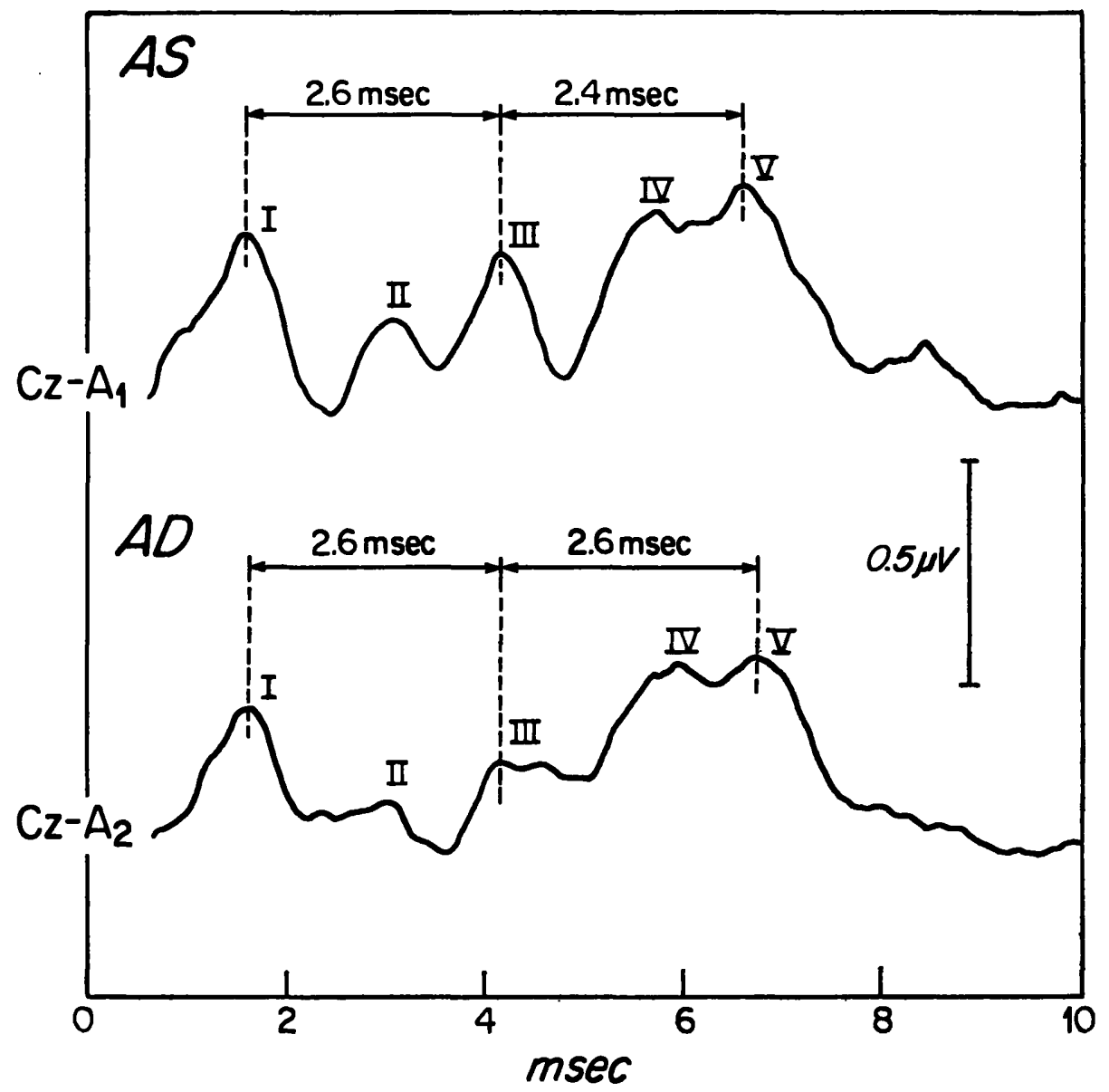

Fig. 3 - Case of probable Friedreich's ataxia. The wave I-III IL are at the upper limits of normal, and the III-V and I-V IL are prolonged. 


\section{DISCUSSION}

The use of the BAER in the evaluation of peripheral hearing loss is outside the scope of this article. However, one has to identify wave I to infer the integrity of the peripheral hearing apparatus in each patiene. BAERs have been considered helful in the study of comatose patients 12,17. It can differentiate metabolic from structural causes of coma. In the former, the BAERs are normal, as they are in deep coma secundary to drug overdose 21. If a technical or otologic problem can be ruled out the absense of BAERs or of all waves beyond wave I, has a very poor prognosis. These condiitions are found in patients who meet the criteria for brain death ${ }^{19}$. Greenberg et al. 8 also found BAERs of prognostic value in post-traumatic coma.

Chiappa et al. 4 have shown BAER abnormalities in patients with multiple sclerosis (MS): $37 \%$ of patients with and $21 \%$ of patients without symptoms or signs of brainstem lesions. Loss of amplitude of waves IV \& V was found in $88 \%$ of the patients with abnormal BAERs. Thus, it appears to be a reliable clinical test in MS patients. Chiappa ${ }^{2}$ further suggests that the smallest plaque in the auditory system can cause a marked conduction abnormality. Indeed, despite such marked abnormalities it is rare to find conventional auditory acuity losses in MS patients ${ }^{13}$. Cases of MS have been described where all waves beyond wave I are lost on the affected side, yet hearing is preserved on that side 24. There have been suggestions in the literature that the BAER might play a role in evaluating effectiveness of new therapies in MS 4.

One of the best indications for BAERs, because of the therapeutic implications, is the early diagnosis of posterior fossa tumor. Abnormal IL (I-V or I-III) are the most sensitive indicators of extra-axial posterior fossa tumor. All the 25 patients with acoustic neuromas and cerebello-pontine angle meningiomas presented by Parker et al. 11 showed an abnormal BAER on the side of the tumor, while 5 had normal CT-scan and 2 had normal standard audiometry.

In intra-axial posterior fossa tumors, particularly gliomas, the BAER has also been considered a very sensitive test. Abnormal I $-\mathrm{V}$ or III $-\mathrm{V}$ IL are usually seen. A decrease of IL after radiotherapy, associated with clinical improvement has been described ${ }^{21}$. Stockard (personal communication) pointed out the exquisite sensitivity of the BAER in detecting posterior fossa tumor (107 abnormal out of 110 cases in his personal experience).

Brainstem infarcts and hemorrhages are associated with abnormal BAERs when they involve the auditory lemniscal pathway in the pons or midbran. Abnormal BAERs have also been found in sleep-apnea syndrome, hereditary sensorimotor neuropathy ${ }^{24}$, central pontine myelinolysis ${ }^{20}$, leukodystrophies ${ }^{10}$ and olivopontocerebellar degeneration ${ }^{6}$. The diagnostic value of the BAER may be applied to newborns ${ }^{18}$. A differential development of the BAERs in healthy and high-risk infants is proposed by Salamy et al. 15.

A potentially very important recent application of the BAER is to demonstrate abnormality in patients with syndromes previously considered of "functional" or psychiatric origin, such as spastic dysphonia 16 or postconcussion dizziness 14 . 


\section{SUMMARY}

The tecnique that we use for eliciting brainstem auditory evoked responses (BAERs) is described. BAERs are a non-invasive and reliable clinical test when carefully performed. This test is indicated in the evaluation of disorders which may potentially involve the brainstem such as coma, multiple sclerosis posterior fossa tumors and others. Unsuspected lesions with normal radiologic studies (including CT-scan) can be revealed by the BAER.

\section{RESUMO}

\section{Potencial evocado auditivo: aplicação em Neurologia.}

Potencial evocado auditivo (PEA) de curta latência é o conjunto de ondas elétricas registradas no couro cabeludo durante os primeiros dez milisegundos após estimulação auditiva padronizada. Este exame exige um computador que realize a promediação, isto é, que tenha capacidade de registrar a média das respostas e excluir os ruídos (EEG, artefatos musculares e de movimentos). As ondas resultantes são denominadas de I a VII e, provavelmente, representam a ativação do nervo acústico (onda I), núcleos cocleares (onda II), complexo olivar superior (onda III), trato e núcleo do lemnisco lateral (onda IV), colículos inferiores (onda V), corpo geniculado medial (onda VI) e radiação auditiva para o lobo temporal (onda VII). As ondas I, III e V (nervo acústico, ponte e mesencéfalo) são as ondas mais proeminentes e fidedignas. As ondas VI e VII, pela variabilidade, não são úteis na interpretação clínica do teste. $O$ PEA é indicado na avaliação de doenças que potencialmente acometem o tronco cerebral, assim permitindo o estudo de comas, esclerose múltipla, tumores de fossa posterior e outras patologias. Lesões sub-clínicas com exames radiológicos normais (incluindo tomografia computadorizada) podem ser reveladas pelo PEA. O valor diagnóstico do PEA tem também sido mostrado na avaliação de patologias neurológicas em recém-nascidos.

\section{REFERENCES}

1. CANN J. \& KNOTT J. - Polarity of acoustic click stimuli for eliciting brainstem auditory evoked responses: a proposed standard. Am. J. EEG Technol. 19:124, 1979.

2. CHIAPPA K. H. - Pattern shift visual, brainstem auditory, and short-latency somatosensory evoked potentials in multiple sclerosis. Neurology (Minneapolis) 30:110, 1980.

3. CHIAPPA K. H.; GLADSTONE K. J. \& YOUNG R. R. - Brainstem auditory evoked responses: studies of waveform variations in 50 normal human subjects. Arch. Neurol. (Chicago) 26:81, 1979.

4. CHIAPPA K. H.; HARRISON J. L.; BROOKS E. B. \& YOUNG R. R. - Brainstem auditory evoked responses in 200 patients with multiple sclerosis. Ann. Neurol. 7:135, 1980.

5. GALAMBOS R. \& HECOX K. - Clinical applications of the brainstem auditory evolked potentials. Progress in Clinical Neurophysiology vol. 2: Auditory Evoked 
Potentials in Man. Psychopharmacology Correlates of Evoked Potentials 1-19, 1977. Ed. J. E. Desmedt. Karger, Basel.

6. GILROY J. \& LYNN G. E. - Computerized tomography and auditory-evoked potentials: Use in the diagnosis of olivopontocerebellar degeneration. Arch. Neurol. (Chicago) 35:143, 1978.

7. GOLDIE W. D.; CHIAPPA K. H.; YOUNG R. R. \& BROOKS E. B. - Brainstem auditory and short-latency somatosensory evoked responses in brain death. Neurology (Minneapolis) 29:551, 1979.

8. GREENBERG, R. P.; MARTIN D. J.; BECKER D. P. \&MILLER J. D. Evaluation of brain function in severe human head trauma with multimodality evoked potentials. J. Neurosurg. 47:150, 1977.

9. JEWELL D. L. \& WILLISTON J. S. - Auditory evoked for fields average from the scalp of humans. Brain 94:681, 1971.

10. OCHS R.; MARKAND O. N. \& DEMYER W. E. - Brainstem auditory evoked responses in leukodystrophies. Neurology (Mineapolis) 29:1089, 1979.

11. PARKER S. W.; CHIAPPA K. H. \& BROOKS E. B. - Brainstem auditory evoked responses in patients with acoustic neuromas and cerebello-pontine angle meningiomas. Neurology (Minneapolis) 30:413, 1980.

12. PLUM F. \& POSNER J. B. - The diagnosis of Stupor and Coma, Third edition. F. A. Davis Company, Philadelphia, 1980.

13. ROBINSON K. \& RUDGE P. - Abnormalities of the auditory evoked potentials in patients with multiple sclerosis. Brain 100:19, 1977.

14. ROWE J. J. \& CARLSON C. - Brainstem auditory evoked potentials in postconcussion dizziness. Arch. Neurol. (Chicago) 37:679, 1980.

15. SALAMY A.; MENDELSON T.; TOOLEY W. H. \& CHAPLIN E. R. - Differential development of brainstem potentials in healthy and highrisk infants. Science 210:553, 1980.

16. SHARBROUGH F. W.: STOCKARD J. J. \& ARONSON A. E. - Brainstem auditoryevoked responses in spastic dysphonia. Trans. Am. Neurol. Assoc. 103:198, 1978.

17. STARR A. - Clinical relevance of brainstem auditory evoked potentials in brainstem disorders in man. Progress in Clinical Neurophysiology vol. 2: Auditory Evoked Potentials in Man. Psychopharmacology Correlates of Evoked Potentials: 45-57, 1977. Ed. J. E. Desmedt. Karger, Basel.

18. STARR A.; AMLIE R. N.; MARTIN W. H. \& SANDERS S. - Development of auditory function in newborn infants revealed by auditory brainstem potentials. Pediatrics 60:831, 1977.

19. STOCKARD J. J. \& ROSSITER V. S. - Clinical and pathologic correlates of brainstem auditory response abnormalities. Neurology (Minneapolis) 27:316, 1977.

20. STOCKARD J. J.; ROSSITER V. S.; WIEDERHOLT W. C. \& KOBAYASHI R. M. - Brainstem auditory evoked responses in suspected central pontine myelinolysis. Arch. Neurol. (Chicago) 33:726, 1976.

21. STOCKARD J. J. \& SHARBROUGH F. W. - Unique contributions of shortlatency auditory and somatosensory evoked potentials to neurologic diagnosis. In: Clinical Uses of Cerebral, Brainstem and Spinal Somatosensory Evoked Potentials. Ed. J. E. Desmedt, Karger, Basel, 1980. 
22. STOCKARD J. J.; SHARBROUGH F. W. \& TINKER J. S. - Effects of hypothermia on the human brainstem auditory response. Ann. Neurol. 3:368, 1978.

23. STOCKARD J. J.; STOCKARD J. E. \& SHARBROUGH F. W. - Nonpathologic factors influencing brainstem arditory evoked potentials. Am. J. EEG Technol. 18:177, 1978.

24. STOCKARD J. J.; STOCKARD J. E. \& SHARBROUGH F. W. - Brainstem auditory evoked potentials in neurology: methodology, interpretation, clinical application. In: Electrodiagnosis in Clinical Neurology, editor Aminoff, M. J., Ed. Churchill-Livingstone, New York, 1980.

25. STOCKARD J. J.; STOCKARD J. E.; WESTMORELAND B. F. \& CORFITS J. F. - Normal variation of brainstem auditory evoked potentials as a function of stimulus and subject characteristics. Arch. Neurol. (Chicago) 36:823, 1979.

Departamento de Neurologia - Fraculdade de Ciencias Médicas - Universidade Estadual de Campinas - Caixa postal 1170 - 18100 Campinas, SP - Brasil. 